\title{
Olfactory Cues from Pathogenic Fungus Affect the Direction of Motion of Termites, Coptotermes formosanus
}

\author{
Aya Yanagawa ${ }^{1}$ - Tomoya Imai ${ }^{1} \cdot$ Toshiharu Akino ${ }^{2}$. \\ Yoshihiro Toh ${ }^{3}$. Tsuyoshi Yoshimura ${ }^{1}$
}

Received: 12 January 2015 / Revised: 26 July 2015 / Accepted: 26 October 2015 /Published online: 12 November 2015

(C) Springer Science+Business Media New York 2015

\begin{abstract}
Formosan subterranean termites, Coptotermes formosanus, tend to avoid pathogen odors when tested in Ytube olfactometers, but approach and groom exposed nestmates to remove pathogens from their cuticle and maintain a healthy population. To better understand their differential reaction to pathogens and their odors, the relationship between odor cues and direction of motion was examined with the fungus Isaria fumosorosea $\mathrm{K} 3$ strain. The results indicate that nestmate odor was strongly attractive only in tests where fungal odors were present in both branches of the olfactometer. Termites generally avoid fungal odors when offered a choice without fungal odor. We also tested termite aversion to 3-octanone and 1-octen-3-ol, major surface chemical compounds of I. fumosorosea $\mathrm{K} 3$, and estimated the total mass of these compounds present on the conidial surface by direct extraction method. The total quantity of these chemicals on the surface of fungal conidia was estimated to be approximately $0.01 \mathrm{ng}$ per $10^{7}$ conidia. This study demonstrates a context dependent behavioral change in termites in response to the odors of pathogenic fungi.
\end{abstract}

Electronic supplementary material The online version of this article (doi:10.1007/s10886-015-0649-8) contains supplementary material, which is available to authorized users.

Aya Yanagawa

ayanagawa@rish.kyoto-u.ac.jp

1 Research Institute for Sustainable Humanosphere, Kyoto University, Uji 611-0011, Japan

2 Laboratory of Applied Entomology, Kyoto Institute of Technology, Ukyo-ku, Kyoto 616-8354, Japan

3 Department of Biology, Faculty of Science, Kyushu University, Higashi-ku, Fukuoka 812-8581, Japan
Keywords Coptotermes formosanus - Isaria fumosorosea . Hexane extraction $\cdot 3$-octanone $\cdot$ 1-octen-3-ol .

Directional choice

\section{Introduction}

Many insects have evolved behavioral immunity to pathogens, and either avoid or remove disease causing agents. At the same time, entomopathogenic microbes like fungi may have developed novel surface compounds to counteract behavioral immunity of their host insects (Roode and Lefévre 2012). Since entomopathogenic fungi vary greatly with regard to competitive strength, attachment pattern, germination ability, and environmental adaptability (Clarkson and Charnley 1996), the cues that lead insects to detect the presence of pathogens are not yet clear. Furthermore, insect behavior often is focused on obtaining environmental information more than responding to stimuli. Important signals often are concealed in the high level of background noise in insect habitats (Schroeder and Hilker 2008). Neural circuits perceive, transmit, interpret, and relay feedback messages. There also is fine tuning and signal reduction at the periphery of the nervous system (Webb 2012), which sometimes bring behavioral changes in response to external signals. The interactions between olfactory perception and behavior are still unclear.

The Formosan subterranean termite, Coptotermes formosanus Shiraki (Blattodea: Rhinotermidae), is one of the most destructive insects in homes and other wooden structures (Lax and Osbrink 2003; Mulrooney et al. 2007). Various pesticides have been used for termite control, but their extensive use represents a significant environmental hazard (de Faria and Wraight 2007; Zoberi 
1995). Entomopathogenic fungi have been proposed as an alternative agent for termite control (Culliney and Grace 2000; Rath 2000; Sun et al. 2008; Verma et al. 2009), but fungal pathogens have not always been as successful as chemical controls (Chouvenc et al. 2011). It is important to learn how termites avoid and remove microbial biological control agents in their natural habitat in order to develop reliable biocontrol applications. Coptotermes formosanus tends to avoid pathogen odors, yet the termites approach and groom exposed nestmates to remove pathogens from their bodies (Yanagawa et al. 2012). Recent studies show that termite grooming is a contextdependent behavior, as the frequency of grooming reflects the termites' ability to identify the microbial contamination of their nestmates (Yanagawa et al. 2010, 2011a). The conidia of the K3 strain are removed effectively from the termite cuticle via mutual grooming (Yanagawa et al. 2008) even though conidial odors elicit clear avoidance behavior in C. formosanus (Yanagawa et al. 2012).

There are several reports describing insect attraction and aversion to fungal odors (Cornelius et al. 2004; Mburu et al. 2009, 2013; Stamets 2012), but little is known about insectpathogen interactions from the perspective of insect behavior (Jackson et al. 2010). Previous analysis of the chemical constituents of the odors found in I. fumosorosea (including the $\mathrm{K} 3 \mathrm{strain}$ ) detected an average of $3.2 \mathrm{ng} / \mathrm{ml} \mathrm{3-octanone} \mathrm{and}$ $1.2 \mathrm{ng} / \mathrm{ml} \mathrm{1-octen-3-ol} \mathrm{in} \mathrm{(Yanagawa} \mathrm{et} \mathrm{al.} \mathrm{2012).} \mathrm{These}$ chemicals are major surface components of this strain, and our previous analyses with solid phase microextraction (SPME) fibers and monolithic material sorptive extraction (MMSE) disks could provide only indirect estimations of chemical quantity, as the fungal volatiles were collected from the air overnight (Yanagawa et al. 2011b, 2012, respectively). Despite our indirect estimations of chemical quantities, the activity of these fungal odors is clear.

In this study, the associations between olfactory perception and termite hygiene behavior were examined by using C. formosanus and the fungus Isaria fumosorosea Wize (Hypocreales: Cordycipita- ceae), which is a well-known agent for the biological control of pest insects (Ferron 1981; Vega et al. 2009). We used Y-tube olgactometers to examine termite context-dependent behavioral change in response to fungal odors. We estimated the chemical quantity on the conidium surface directly by a hexane extraction using the two indicator chemicals, 3-octanone and 1-octen-3-ol, which are the main surface volatiles of $I$. fumosorosea K3. Additionally, electron microscopic observation was conducted on antennal sensilla trichodeum I and basiconica, which have chemosensillum external structures (Yanagawa et al. 2009b). Our study demonstrated that the termites carefully approach the pathogen under several conditions and provide a novel perspective for investigating the behavioral resistance of termites to fungi in nature.

\section{Methods and Materials}

Insects Mature workers of Coptotermes formosanus were obtained from a laboratory colony that was maintained in the dark at $28^{\circ} \mathrm{C}$ and at more than $85 \%$ R.H. at the Deterioration Organism Laboratory (DOL) of the Research Institute for Sustainable Humanosphere, Kyoto University, Japan. In this study, the largest colony (from Okayama, Japan) in DOL was used since individuals from three DOL colonies showed no significant difference in aversion to the odor of I. fumosorosea K3 (Yanagawa et al. 2012).

Worker termites were separated into two groups, I and II, to visualize the treatment on each termite. They were placed in Petri dishes $(90 \times 15 \mathrm{~mm})$ that held a filter paper (about $90 \mathrm{~mm}$ diam., Whatman No 1) impregnated with distilled water (group I) or an aqueous solution of $0.05 \%$ (wt/wt) Nile blue A (group II). Treating termites with Nile blue A is known not to cause any significant influence on termite behaviors (Yanagawa et al. 2011a). After treatment, the insects were kept at $25^{\circ} \mathrm{C}$ for $1-2$ weeks before use in the bioassay. This treatment stained all of the termites in group II blue.

Fungus Preparation Isaria fumosorosea K3 was maintained on L-broth agar ( $1 \%$ polypeptone, $0.3 \%$ yeast extract, $2.0 \%$ sucrose, $0.5 \% \mathrm{NaCl}, 2.0 \%$ agar) at $25{ }^{\circ} \mathrm{C}$. Conidia were harvested with a brush from 10 to 15 -days-old cultures and suspended in a $0.025 \%$ aqueous solution of Tween 20 for the behavioral tests and in distilled water for the odor analysis.

Conidia in suspensions were counted with a Thoma hemocytometer (Erma INC. Tokyo) and adjusted to a concentration of $1.0 \times 10^{7}$ conidia $/ \mathrm{ml}$. To investigate concentrationdependent behaviors, they were diluted $10^{0}-, 10^{1}-, 10^{2}-, 10^{3}$ and $10^{4}$-fold.

Grooming Induces Movement Towards the Pathogen Five termites were place into a petri dish to measure grooming in the presence of fungal conidia. Individual fungus-treated nestmates from group II (stained blue) were treated and mixed with four untreated nestmates from group I. Termites from group II were treated with conidia by submerging them in $10^{7}$ conidia/ml suspension in a microcentrifuge tube, gently swirling them for $5 \mathrm{~s}$, and then placing them on a filter paper to dry. Those from group Iwere treated identically with $0.025 \%$ Tween 20 solution without conidia. All termites were placed in a Petri dish $(35 \times 15 \mathrm{~mm})$ and covered with an open lid cardboard box during the experiments to maintain dim lighting while still allowing photographs to be taken without disturbing the termites. The number of mutual contacts between termites was counted to estimate grooming because the duration of grooming behavior varied, and it was difficult to classify this behavior (Yanagawa et al. 2010, 2011a). After a 15-min interval to acclimate termites, the number whose mouth parts contacted other individuals was counted every 
30 s for 15 min by using digital photographs. The total number of contacts recorded every $5 \mathrm{~min}$ was calculated for the data analysis. As a control, this procedure was repeated using termites from both groups that had been submerged only in $0.025 \%$ Tween 20 solution. Data were collected from 20 replicates.

Aversion to Fungus-related Odor Y-tube tests were conducted to examine termite olfactory perception to I. fumosorosea before contact. To estimate the aversion to the fungus-related odor, the concentration-dependent directional response of termites to I. fumosorosea $\mathrm{K} 3$ strain was estimated first. One branch in the $\mathrm{Y}$ contained the air from $1 \mathrm{ml}$ of $1.0 \times 10^{3}-10^{7}$ $/ \mathrm{ml}$ of conidial suspension, and the other contained $1 \mathrm{ml}$ of $0.025 \%$ Tween 20 solution as a control. Thirty replicates were performed at each concentration. To estimate the impact of additional olfactory cues on the aversive reaction, paper discs $(1 \times 1 \mathrm{~cm})$ and ten nestmates were used. Termites were placed into a bottle $(30 \mathrm{ml})$ as a source of olfactory stimulus. Five stimulus combinations with three controls were prepared with nestmates and filter paper discs, set 1 through set 8 . In all Ytube tests, branch preference was converted to a percentage. Thirty individuals were examined for each set. These experiments were carried out in the laboratory at $25^{\circ} \mathrm{C}$ under normal light conditions.

The Y-tube olfactometer was prepared as in Yanagawa et al. (2012). In brief, the Y-tube olfactometer consisted of a Y-shaped glass tube with an inner diam of $6 \mathrm{~mm}$. The single stem branch and two side branches were each $5 \mathrm{~cm}$ long and at an angle of $60^{\circ}$. Stimulus and control air both flowed into the stem branch from their respective side branches. Fresh air was pumped into the system using a diaphragm pump (AP-115 Iwaki air pump, IWAKI CO. LTD, Tokyo) and cleaned through serially connected bottles containing silica gel, 3 and $5 \AA$ molecular sieves, and active carbon. The cleaned air flow was divided into two channels by a Y-shaped connector. Each air channel was connected to a bottle $(30 \mathrm{ml})$ that contained stimulus odors, which was then connected to each branch of the Y-tube olfactometer. The flow in each channel was regulated to be $400 \mathrm{ml} / \mathrm{min}$ by an inline flowmeter. One termite was placed at the inlet of the stem branch of the Y-tube and exposed to light illumination from its abdominal side to drive it to move to the branch point of the Y-tube. To determine the time required for the termite to choose either of the two side branches of the Y-tube olfactometer, we measured termite choice and the time that the termite took to reach the mid-point of the respective side branch $(2.5 \mathrm{~cm}$ from the junction) from the entrance of the stem branch and from the middle of the stem branch $(2.5 \mathrm{~cm}$ from the entrance). A "choice" was made when the sample termite passed the mid-point of the respective side branch $(2.5 \mathrm{~cm}$ from the junction).
Quantity of Odor Compounds on Conidia To directly evaluate chemical quantities on the surface of $10^{7}$ conidia, 3octanone and 1-octen-3-ol (Nacalai Tesque, Kyoto, Japan) were used as indicator chemicals. Conidial suspensions $\left(10^{7}\right.$ $/ \mathrm{ml}$ ) were prepared in $1 \mathrm{ml}$ deionized water and freeze-dried in a glass tube until they became dried-conidia powder. The compounds on the conidia surface were extracted for $5 \mathrm{~min}$ with $1 \mathrm{ml}$ hexane (Nacalai Tesque, Japan), and conidia were filtered from hexane solution. In the control, $1 \mathrm{ml}$ deionized water was freeze-dried in a glass tube, which was then rinsed with $1 \mathrm{ml}$ hexane. The hexane was concentrated to $200 \mu \mathrm{l}$ before analysis. The quantity of adsorbed chemicals was estimated by gas chromatograph-mass spectrometry (GC/MS) using a Shimadzu QP5000 GC-MS system. EI-mass spectra were obtained at $70 \mathrm{eV}$. 3-Octanone and 1-octen-3-ol were identified by comparison of their mass spectra and retention times to those of the respective authentic compounds, and the quantity of each chemical in $10^{7} / \mathrm{ml}$ conidia was estimated by comparison of the peak areas to $10 \mathrm{ng} / \mathrm{ml}$ external standards. Each determination was repeated five times.

Termite sensitivity to these two chemicals was examined by Y-tube olfactometer. Y tube tests identical to previous methods were run to examine the choice between known quantities of a single chemical suspended in $1 \mathrm{ml}$ deionized water and $1 \mathrm{ml}$ deionized water alone. Serial dilutions were made using $1 \mu \mathrm{l} / \mathrm{ml}$ solutions of a single chemical (about $8 \mathrm{ng} / \mathrm{ml}$ for both chemicals).

\section{Electron Microscopy of Chemo-sensillum on Antenna of} C. formosanus Termite antennae were examined with a scanning electron microscope (SEM). Sample antenna were fixed in $4 \%(\mathrm{v} / \mathrm{v})$ osminium tetroxide for $2 \mathrm{~h}$ and then dehydrated through a graded acetone series. Samples were air dried and coated with platinum-palladium. Observation was made with a Hitachi S-4100 SEM, which was equipped with a field emission gun. For transmission electron microscopic (TEM) observation, antennae were double-fixed in $3 \%$ glutaraldehyde and $2 \%$ osmium tetroxide, dehydrated through graded ethanol solutions, and embedded in Epon 812. Thin sections were double-stained with uranyl acetate and lead tartrate, and observed by TEM (JEM-2000 EX II). Chemosensillum identity was confirmed by series of thin sections.

Statistical Analysis A Poisson regression was applied to examine the frequency of mutual-contacts, and then linear regression was applied to see the time-dependent increase of mutual-contacts. Kruskal-Wallis test was used to analyze all of the data from the Y-tube test to compare termite reaction among sets. Linear regression analysis (y: $y=1$ when the termite chose a test odor branch, and $y=0$ when the termite chose a control solution branch, $\mathrm{x}$ : concentration of conidia solution) was applied to see the concentration dependence in each set. Concentration-dependent reactions in the Y-tube olfactometer 
also were analyzed by the Wilcoxon test in comparison with the control choice. For a more detailed analysis of olfactory responses, multiple pairwise comparisons were employed. To examine the influence of olfactory cues on termite behavior, the Tukey-Kramer HSD test was applied. JMP 10.0 software was used for all analyses.

\section{Results}

Grooming Induces Movement Towards the Pathogen Termites moved toward their fungus-treated nestmates, and removed these pathogenic organisms from other termites. The frequency of mutual touching for all five termites (one treated + four untreated) are shown in Fig. 1a. Mutual contacts were higher in fungus-treated groups compared to control groups $\left(P<0.001, \chi^{2}=28.98\right.$ at group parameter in Poisson regression). Mutual contacts also increased in frequency over time in the fungus treated group $(P<0.001, T=3.76$ at time parameter in linear regression) but not in the control group $(P=$ $0.951, T=0.06$ at time parameter in linear regression). Contact directed toward treated blue-termites was significantly greater than that directed toward control blue-termites $\left(P<0.001, \chi^{2}=\right.$ 87.67 at group parameter in Poisson regression, test groups: $P=0.006, T=2.88$ and control groups: $P=0.784, T=-0.28$ at time parameter in linear regression) (Fig. 1b).

Aversion to the Fungus Odor Termite aversion to the odor of I. fumosorosea $\mathrm{K} 3$ increased significantly with an increase in concentration (Table 1, $P<0.001, \chi^{2}=23.23$ in Kruskal-Wallis test). At the highest concentration $\left(10^{7}\right.$ conidia $\left./ \mathrm{ml}\right)$, termites exhibited an avoidance in a significantly shorter time than for more dilute conidia of the fungal odors $\left(P=0.026, \chi^{2}=\right.$ 4.991 in Wilcoxon test).

\section{Effects of Multiple Olfactory Cues on the Termite Aversive}

Reaction Multiple olfactory cues were examined with eight sets as described in Fig. 2a. These sets were designed to see if termite aversion to fungus odor could be modulated by other factors like filter paper discs or presence of nestmates. Sets 1 to 3 were controls. The introduction of additional olfactory stimuli resulted in context-dependent behavioral change in
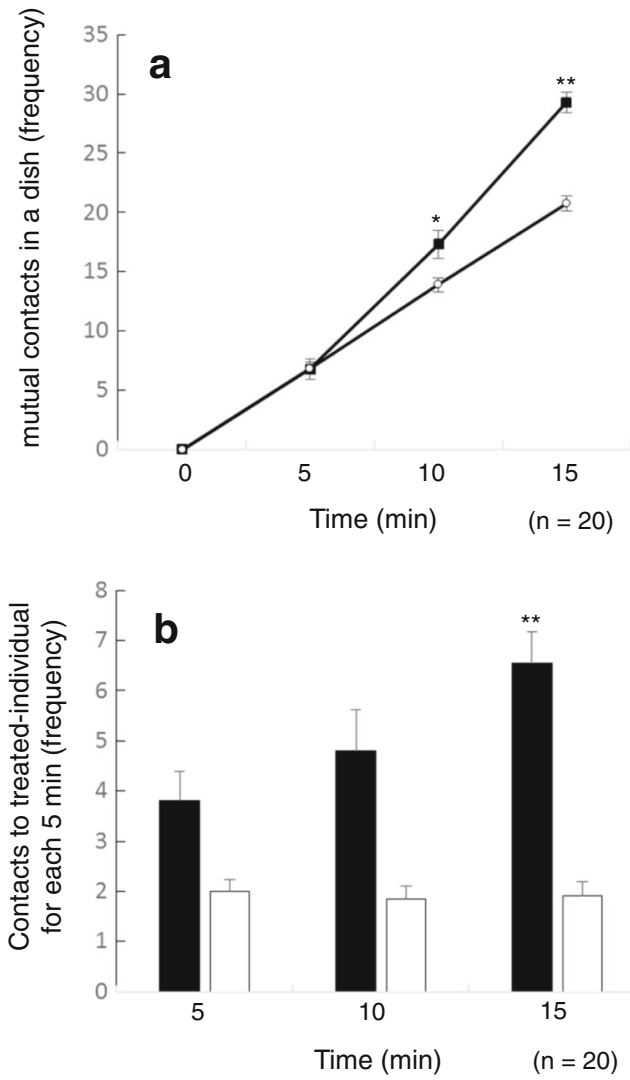

Fig. 1 Grooming behavior as reflected by the frequency of mutual contact among all five termites observed in a dish for $15 \mathrm{~min}$ (a) and the average number of mutual contacts involving the single fungal treated or control termite (stained with $0.05 \%$ Nile blue A) during the $15 \mathrm{~min}$ assay (b). Each dish contained five termites $(N=20)$ treated with either Tween 20 (open circles, white bars) or $10^{7}$ conidia $/ \mathrm{ml}$ of Isaria fumosorosea K3 closed circles, black bars. The vertical bars indicate standard errors (SE). Significant changes are indicated by asterisks (Wilcoxon test **: $P<0.01, *: P<0.05$ )

termite directional choice, and in their aversion to the pathogen (Table 2, $P<0.001, \chi^{2}=43.9584$, Kruskal-Wallis test: set 4 - set 8).

Fungal odors were avoided dramatically by termites compared to Tween 20 (tw) controls, as is seen in set 4 (Fig. 2a) $\left(P<0.001, \chi^{2}=12.17\right.$, Wilcoxon test: set $1 /$ set 4$)$. There was a significant difference in termite choice between set 5 and set 6 ( $P=0.018, \chi^{2}=5.62$, Wilcoxon test) but no significant difference between set 4 and set $5\left(P=0.321, \chi^{2}=0.985\right.$, Wilcoxon

Table 1 Concentration-dependent avoidance to Isaria fumosorosea K3 conidial suspension. Percent (\%) of stimulus odor chosen in Y-maze test. (mean value $\pm \mathrm{SE}, n=30$ )

\begin{tabular}{|c|c|c|c|c|c|c|}
\hline Number of conidia $(/ \mathrm{ml})$ & Control & $10^{3}$ & $10^{4}$ & $10^{5}$ & $10^{6}$ & $10^{7}$ \\
\hline Preference $(\%)$ & $56.7 \pm 9.2$ & $33.3 \pm 8.8$ & $* * 23.3 \pm 7.9$ & $* * * 13.3 \pm 6.3$ & $* * * 13.3 \pm 6.3$ & $* * * 13.3 \pm 6.3$ \\
\hline Time taken to pass Y-maze (sec) & $28.5 \pm 4.6$ & $35.8 \pm 6.8$ & $27.4 \pm 6.0$ & $30.4 \pm 6.5$ & $37.2 \pm 6.4$ & $* 18.2 \pm 3.4$ \\
\hline
\end{tabular}

Significant changes from the control response were examined by Wilcoxon test

$(* * *: P<0.001, * *: P<0.01, *: P<0.05)$ 


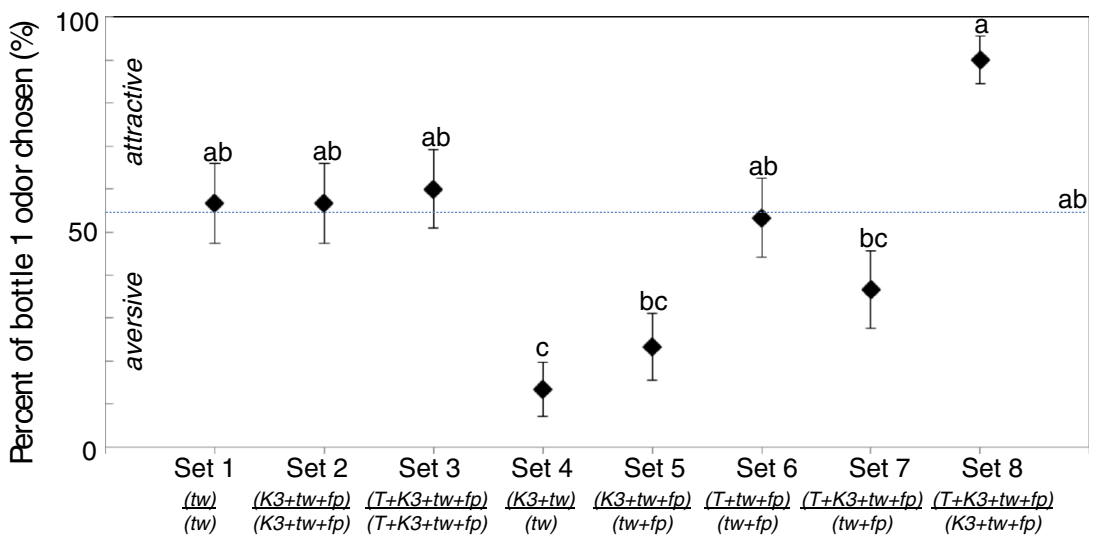

Fig. 2 Behavioral modification in response to multiple olfactory cues. Results of two choice olfactometer tests measuring the percentage of termites choosing bottle 1 . The dotted line indicates the control percent of termites choosing bottle 1 under no cue conditions $(N=30,53.3 \pm$ $9.26 \%$ individuals chose bottle 1 direction in $10.1 \pm 8.45 \mathrm{~min}$ when both bottles 1 and 2 were empty). Lettering indicates the result of the

test), set 5 and set $7\left(P=0.264, \chi^{2}=1.249\right.$, Wilcoxon test $)$, or between set 6 and set $7\left(P=0.198, \chi^{2}=1.655\right.$, Wilcoxon test $)$ (Fig. 2a). This suggests that the aversion to the fungal odor was not affected by other odors in the source bottle. In addition, the odor from nestmates did not encourage the individual choice of direction in comparison with controls $(P=0.956$, $\chi^{2}=0.090$ : set $1,2,3$ and $P=0.965, \chi^{2}=0.269$, KruskalWallis test: set 1, 2, 3, 6). However, when the stimulus air from both branches of the Y-tube olfactometer contained a fungal odor, termites showed a strong preference for air that also contained the odor of their nestmates (Choice of test branch: $90.0 \pm 5.6 \%, P=0.004, \chi^{2}=8.381$ in set $2 /$ set 8 and $P<0.001, \chi^{2}=18.067$ in set $7 /$ set 8 , Wilcoxon test)(Fig. 2a). It took a similar amount of time for termites to make their choice in all test sets (Table 3, Tukey-Kramer HSD test).

Quantity of Odor Compounds in Fungus Surface extracts of I. fumosorosea conidia were screened for 3-octanone and 1octen-3-ol by GC/MS. Several compounds were detected at very low level by $5 \mathrm{~min}$ of extraction with hexane, but 3octanone and 1-octen-3-ol were sufficiently concentrated for
Tukey-Kramer HSD test. Error bars indicate a standard error (SE) $(N=$ 30). Sets 1-8 were described as: [bottle 1]/[bottle2]. The following abbreviations are used to describe odor sources used for all combinations: ' $\mathrm{Tw}$ ' indicates a Tween 20 solution, ' $\mathrm{T}$ ' indicates termites, 'fp' indicates filter paper discs and ' $\mathrm{K} 3$ ' indicates a solution of Isaria fumosorosea $\mathrm{K} 3$

successful identification (Fig. S1). 1-Octen-3-ol was detected in all five replicates, and its concentration was $0.052 \pm$ $0.049 \mathrm{ng} / \mathrm{ml}$ in $10^{7}$ conidia. On the other hand, 3-octanone was detected in only one replicate and was at a concentration of $0.044 \mathrm{ng} / \mathrm{ml}$.

In Y-tube tests, termites showed concentration-dependent avoidance of 3-octanone (Fig. 3a). Termites were most strongly affected by $8.2 \times 10^{-9} \mathrm{ng}$ of 3 -octanone in $1 \mathrm{ml}$ water. Since $10^{7}$ conidia contained 0.044 ng 3 -octanone, termites could sense fungus-related chemicals at levels that were much lower than those in a $10^{7}$ conidia $/ \mathrm{ml}$ suspension. No significant reaction was observed to the solutions of 1-octen-3-ol. There was no association between the time taken to choose a branch and concentration of fungal odors (Table 4, 3-octanone: Pearson's $r=0.65$, 1-octen-3-ol: Pearson's $r=0.32$ ).

Electron Microscopy of Chemo-sensillum on Antenna of C. formosanus Several types of chemo-sensilla, sensilla trichodea, chaetica and basiconica were observed on termite antennae under SEM, and we identified the sensillum basiconica as a chemo-sensillum by TEM (Fig. 4).

Table 2 Combinations of set-ups used for Y-maze test to examine the condition of termite aversion to the fungal odor

\begin{tabular}{|c|c|c|c|c|c|c|c|c|c|c|c|c|c|c|c|c|}
\hline \multirow[t]{2}{*}{ Odor source/set } & \multicolumn{2}{|l|}{ Set 1} & \multicolumn{2}{|l|}{ Set 2} & \multicolumn{2}{|l|}{ Set 3} & \multicolumn{2}{|l|}{ Set 4} & \multicolumn{2}{|l|}{ Set 5} & \multicolumn{2}{|l|}{ Set 6} & \multicolumn{2}{|l|}{ Set 7} & \multicolumn{2}{|l|}{ Set 8} \\
\hline & $\begin{array}{l}\text { Bottle } \\
1\end{array}$ & $\begin{array}{l}\text { Bottle } \\
2\end{array}$ & $\begin{array}{l}\text { Bottle } \\
1\end{array}$ & $\begin{array}{l}\text { Bottle } \\
2\end{array}$ & Bottle 1 & Bottle 2 & $\begin{array}{l}\text { Bottle } \\
1\end{array}$ & $\begin{array}{l}\text { Bottle } \\
2\end{array}$ & $\begin{array}{l}\text { Bottle } \\
1\end{array}$ & $\begin{array}{l}\text { Bottle } \\
2\end{array}$ & $\begin{array}{l}\text { Bottle } \\
1\end{array}$ & $\begin{array}{l}\text { Bottle } \\
2\end{array}$ & $\begin{array}{l}\text { Bottle } \\
1\end{array}$ & $\begin{array}{l}\text { Bottle } \\
2\end{array}$ & $\begin{array}{l}\text { Bottle } \\
1\end{array}$ & $\begin{array}{l}\text { Bottle } \\
2\end{array}$ \\
\hline Fungal conidia & & & $\mathrm{x}$ & $\mathrm{x}$ & $\mathrm{x}$ & $\mathrm{x}$ & $\mathrm{x}$ & & $\mathrm{x}$ & & & & $\mathrm{x}$ & & $\mathrm{x}$ & $\mathrm{x}$ \\
\hline Termites (nestmate) & & & & & $\mathrm{x}$ & $\mathrm{x}$ & & & & & $\mathrm{x}$ & & $\mathrm{x}$ & & $\mathrm{x}$ & \\
\hline Filter paper discs & & & $\mathrm{x}$ & $\mathrm{x}$ & $\mathrm{x}$ & $\mathrm{x}$ & & & $\mathrm{x}$ & $\mathrm{x}$ & $\mathrm{x}$ & $\mathrm{x}$ & $\mathrm{x}$ & $\mathrm{x}$ & $\mathrm{x}$ & $\mathrm{x}$ \\
\hline $0.025 \%$ Tween 20 & $\mathrm{x}$ & $\mathrm{x}$ & $\mathrm{x}$ & $\mathrm{x}$ & $\mathrm{x}$ & $\mathrm{x}$ & $\mathrm{x}$ & $\mathrm{x}$ & $\mathrm{x}$ & $\mathrm{x}$ & $\mathrm{x}$ & $\mathrm{x}$ & $\mathrm{x}$ & $\mathrm{x}$ & $\mathrm{x}$ & $\mathrm{x}$ \\
\hline
\end{tabular}


Table 3 Time taken to pass Y-tube olfactometer (mean value \pm SE)

\begin{tabular}{|c|c|c|c|c|c|c|c|c|}
\hline Sets & Set 1 & Set 2 & Set 3 & Set 4 & Set 5 & Set 6 & Set 7 & Set 8 \\
\hline Time taken to pass Y tube (sec) & $28.5 \pm 4.6 \mathrm{a}$ & $33.8 \pm 4.0 \mathrm{ab}$ & $33.9 \pm 6.8 \mathrm{a}$ & $18.2 \pm 3.4 \mathrm{a}$ & $19.9 \pm 3.2 \mathrm{ab}$ & $27.4 \pm 4.1 \mathrm{ab}$ & $25.7 \pm 3.4 \mathrm{ab}$ & $17.2 \pm 2.4 \mathrm{ab}$ \\
\hline
\end{tabular}

Lettering indicates significantly different mean time (sec.) according to the Tukey-Kramer HSD test $(P<0.05)$. Individuals progressed toward bottle 1 in $10.1 \pm 8.45 \mathrm{~b}$ min when both bottles 1 and 2 were empty

\section{Discussion}

This study demonstrates that termites exhibit contextdependent behaviors in response to the pathogenic fungus I. fumosorosea. To see the effects of other olfactory cues on their avoidance of fungal odors in Y-tube olfactometers, several setups were tested with the pathogen, filter paper discs, and nestmates. While the experimental setting was simple, termites strongly avoided the pathogen odors. They showed clear attraction to nestmate odors only when both choices contained fungal odors in the Y-tube.

Termites showed a rapid, but brief, increase in their contact frequency after one fungus-treated nestmate was placed in a healthy population. The response was likely mediated by olfactory perception (Fig. 1 and Yanagawa et al. 2011a). Termite orientation and movement also changed in relation to olfactory cues in moving air containing the odor of the pathogenic fungus. The Y-tube binary choice test showed that termites avoided the odor of I. fumosorosea $\mathrm{K} 3$, and this effect was clearly concentration-dependent (Table 1). Termites never moved toward the pathogenic fungus odor if they could choose another direction without the odor (Fig. 2, set 4, $5,7)$. Aversion to pathogen odors was not changed significantly by adding other odor sources but was mediated slightly (Fig. 2, set 4 - set 5 and set 5 - set 7). In contrast, when both cues contained the fungus odor, termites showed a significant change in their behavior and chose the cue containing nestmate odor (Fig. 2 set 8 ). These results support the crucial role of olfactory cues in the ability of insects to perceive foreign organisms and the ability termites to survive and avoid harmful pathogens (Chouvenc et al. 2011; Staples and Milner 2000).

The amount of 1-octen-3-ol and 3-octanone detected in a hexane-extraction of $10^{7}$ I. fumosorosea conidia was around $0.05 \mathrm{ng}$ for both compounds. Y-tube tests with a single chemical demonstrated that the termite olfactory system responds to $8.2 \times 10^{-12} \mathrm{ng} / \mathrm{ml}$ of 3 -octanone (Fig. 3a). This concentration of 3-octanone is much less than the amount detected in a hexane-extraction of $10^{7}$ I. fumosorosea conidia, and it suggests that the termite olfactory system can distinguish with very high sensitivity between peripheral inputs. It is reported that soil in Kenya contains $10^{2}-10^{4}$ fungus cells per gram (Varm et al. 1994), and that $10^{3}-10^{5}$ entomopathogenic fungal conidia are present per gram of soil in orchards in Japan (Yaginuma 1990). Therefore, sensitivity could be a necessary ability for soil-dwelling insects to sense pathogens in nature. Odors from fungi do not require a specific receptor, as in pheromone perception, which means they must be classified as generalist cues such as plant or soil odors (Steinbrecht 1999). Previous studies that investigated host identification and herbivory in insects revealed that insects tend to perceive higher concentrations of chemical compounds in their host plants than those detected by termites in this study (SchmidtBüsser et al. 2009; Webster et al. 2010). Webster et al. (2010) reported that volatile compounds can be perceived differently depending on situations, with consequent changes in insect
Fig. 3 Directional choice of termites in response to single chemical in Y-tube olfactometer. Significant changes from the water (control response) are indicated by asterisk (Wilcoxon test $* *: P<0.01, *: P<0.05)$. Error bars indicate a standard error (SE) $(N=30)$.

Concentration-dependent reaction of : 3-octanone and ०: 1-octen3-ol

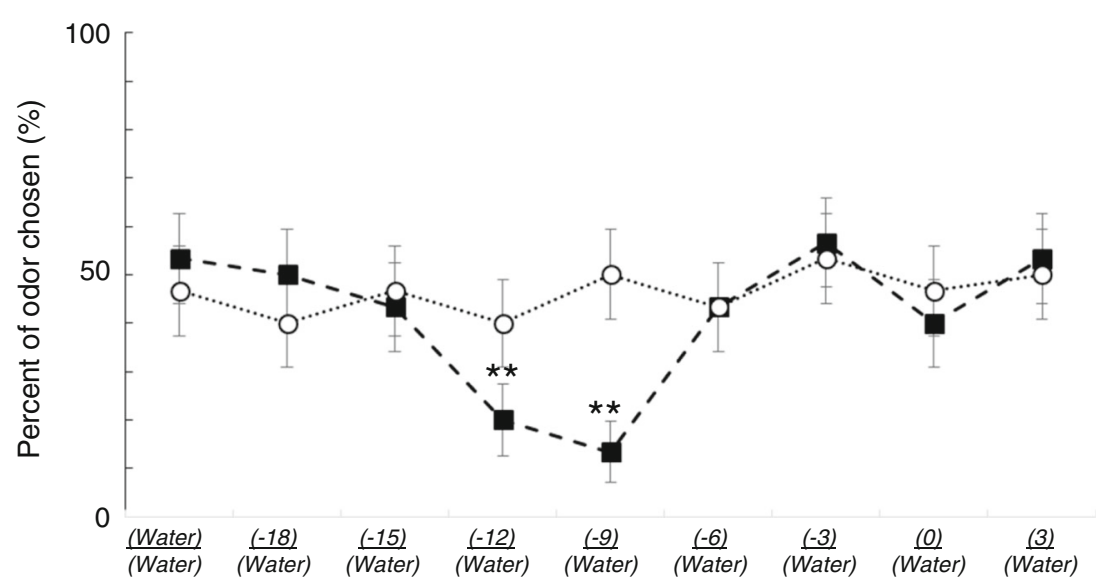

Concentration $\left(8.2 \times 10^{x} \mathrm{ng} / \mathrm{ml}\right)$ in bottle 1 
Table 4 Time taken to pass Y-tube olfactometer (sec)

\begin{tabular}{llllllllll}
\hline $8.2 \times 10^{\times}(\mathrm{ng} / \mathrm{ml})$ & water & $10^{-18}$ & $10^{-15}$ & $10^{-12}$ & $10^{-9}$ & $10^{-6}$ & $10^{-3}$ & $10^{0}$ & $10^{3}$ \\
\hline 3-Octanone & $11.1 \pm 1.7$ & $* * 45.0 \pm 5.0$ & $* * 20.1 \pm 3.3$ & $* * 31.0 \pm 3.6$ & $* * 24.4 \pm 2.4$ & $* 22.8 \pm 3.4$ & $* * 30.8 \pm 3.9$ & $* * 63.2 \pm 7.2$ & $* 22.9 \pm 3.1$ \\
1-Octen-3-ol & $42.9 \pm 3.5$ & $* * 19.0 \pm 3.1$ & $* * 24.3 \pm 2.4$ & $46.5 \pm 6.0$ & $48.5 \pm 4.8$ & $* * 30.8 \pm 4.4$ & $* * 13.4 \pm 2.2$ & $* * 11.7 \pm 2.0$ & $* * 11.6 \pm 2.0$ \\
\hline
\end{tabular}

behavior. For accurate host-recognition in herbivorous insects, perceiving blends of odors also is important since plants generally produce a mix of volatile compounds (Bruce and Pickett 2011). In addition, the compounds shared by both host and non-host plants play an important role in recognition (Cunningham 2012). Thus, it is likely that the relative proportions of chemical blend are cues for perception. Some blends may not induce any response in termites but may play a role in pathogen perception.

The presence of olfactory-receptor-sensilla on termite antennae was confirmed by an electron microscope. There are few reports of termite sensory hairs on termite antennae, especially with SEM and TEM observations, despite the important link between termite habitat/behavior and the modality and quality of sensory information (CostaLeonardo and Soares 1997; Prestage et al. 1963). Moreover, the antennal sensory system of termites may have various features specific to the group (Ishikawa et al. 2007; Rocha et al. 2007; Ziesmann 1996). As for C. formosanus, previously. we presumed the functions of many antennal sensilla from external structures (Yanagawa et al. 2009b). The work of Tarumingkeng et al. (1976) has been the only report describing internal structures. Previously, the role of antennal chemical receptors in grooming behavior was demonstrated (Yanagawa et al. 2009a), and the sensillum chaetica was identified as the sensillum that responds to fungal odor by single sensillum recordings (SSR). However, in the same study, it was indicated that there were some other potential sensilla which can perceive odor (Yanagawa et al. 2010). In the present study, our SEM and TEM image confirm the sensilla basiconica, which are adjacent to a sensillum capitulum, a chemo-receptor sensillum (Fig. 4). Tarumingkeng et al. (1976) also reported the precence of sensilla basiconica, but the sensilla here we report are different from theirs because of their specific location.

It is important to understand how insects perceive pathogens. This knowledge will help develop successful and sustainable pest management. For example, after it was realized that termites do not avoid the blastospore of I. fumosorosea, laboratory tests were begun to develop biological control methods with blastospors (Dunlap et al. 2005; Jackson et al. 1997; Wright et al. 2003). Investigation of insect perception of pathogen-related compounds will help identify compounds that disrupt their behavioral immunity. Balachander et al. (2013) mixed termite attractants in a fungus conidial bait and enhanced the effect of control. If we could isolate a fungal isolate that possesses an attractive or at least indifferent volatile to a target pest, and if it adapts well in the nature of agricultural region for biocontrol, we should be able to control the pest more effectively. Furthermore, several reports have mentioned that environmental factors, such as the soil type, are more important for entomopathogenic fungi than the presence of an insect host (Bouamama et al. 2010; Jackson et al. 2010). Optimizing several environmental factors may be important for ensuring that pathogens persist in the field for sustainable biological control. It appears as though insects carefully use environmental cues that reflect the composition or concentration of chemical information in nature. More studies are needed to clarify the interaction between an odor-cue and insect perception.
Fig. 4 SEM (a) and TEM photo (b) of chemo-sensillum basiconica on antenna of Coptotermes formosanus. a: Arrows indicate chemo-sensillum basiconica. Star indicates a sensillum capitulum. b: Arrows indicate tubules typical of olfactory sensilla
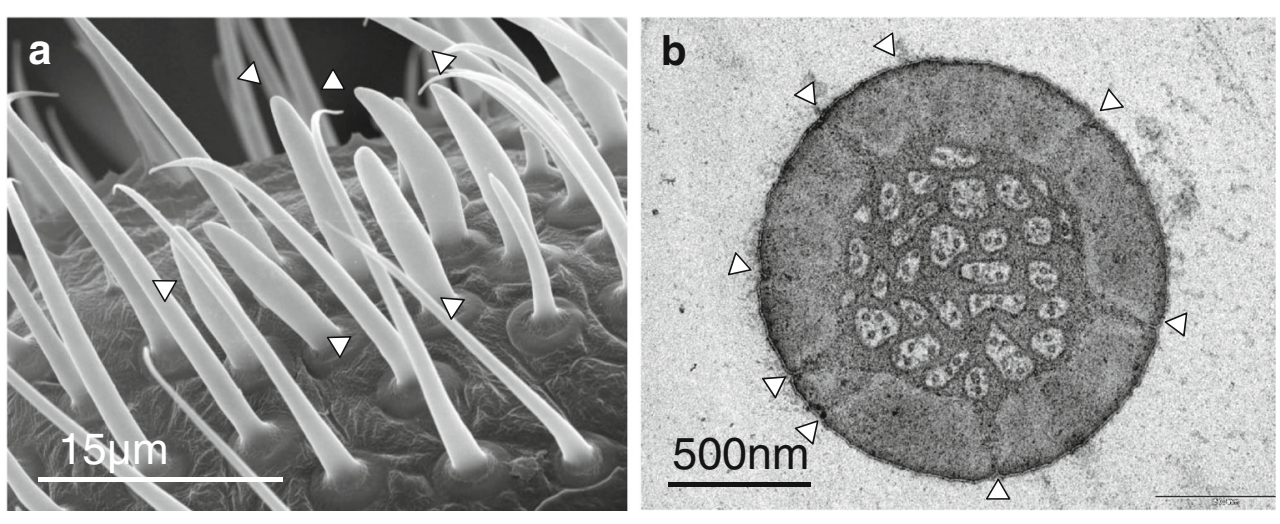
Acknowledgments The authors are grateful to Prof. S. Shimizu (Nishinippon Junior College, Japan) and T. Yanagawa (Kurume University, Japan) for suggestions. We appreciate Prof. F. Yokohari (Fukuoka University, Japan) for discussions on the classification of external structure of termite sensilla, and thank Mr. C. Funaro (NC State University, U.S.) for his comments and English check of the manuscript. The authors also wish to recognize their collaboration with the research program, ADAM, Kyoto University, Japan for the microscopy. Aya Yanagawa was supported by JSPS KAKENHI Grant Number 24880019 and Tsuyoshi Yoshimura was supported by JSPS KAKENHI Grant Number $15 \mathrm{H} 04528$.

\section{References}

Balachander M, Remadevi OK, Sasidharan TO (2013) Dissemination of Metarhizium anisopliae infection among the population of Odontotermes obesus (Isoptera: Termitidae) by augmenting the fungal conidia with attractants. J Asia-Pac Entomol 16:199-208

Bouamama N, Vidal C, Fargues J (2010) Effects of fluctuating moisture and temperature regimes on the persistence of quiescent conidia of Isaria fumosorosea. J Invertebr Pathol 105:139-144

Bruce TJA, Pickett JA (2011) Perception of plant volatile blends by herbivorous insects -finding the right mix. Phytochemistry 72 : 1605-1611

Chouvenc T, Su NY, Grace K (2011) Fifty years of attempted biological control of termites - analysis of a failure. BioControl 59:69-82

Clarkson JM, Charnley AK (1996) New insights into the mechanisms of fungal pathogenesis in insects. Trends Microbiol 4:197-203

Cornelius ML, Bland JM, Daigle DJ, Williams KS, Lovisa MP, Connick WJ, Lax AR (2004) Effect of a lignin-degrading fungus on feeding preferences of Formosan subterranean termite (Isoptera: Rhinotermitidae) for different commercial lumber. J Econ Entomol 97:1025-1035

Costa-Leonardo AM, Soares HX (1997) Morphological aspects of neotropical termite antenna under scanning microscopy. Rev Bras Entomol 41:47-52

Culliney CW, Grace JK (2000) Prospects for the biological control of subterranean termites (Isoptera: Rhinotermitidae), with reference to Coptotermes formosanus. Bull Entomol Res 90:9-21

Cunningham JP (2012) Can mechanism help explain insect host choice? J Evol Biol 25:244-251

de Faria MR, Wraight SP (2007) Mycoinsecticides and Mycoacaricides: a comprehensive list with worldwide coverage and international classification of formulation types. Biol Control 43:237-256

Dunlap CA, Biresaw G, Jackson MA (2005) Hydrophobic and electrostatic cell surface properties of blastospores of the entomopathogenic fungus Paecilomyces fumosoroseus. Colloid Surf B Biointerfaces 46:261-266

Ferron P (1981) Pest control by the fungi Beauveria and Metarhizium. In: Burges HD (ed) Handbook of microbial control of pests and plant disease 1970-1980. Academic, London, pp 465-482

Ishikawa Y, Koshikawa S, Miura T (2007) Differences in mechanosensory hairs among castes of damp-wood termite Hodotermopsis sjostedti (Isoptera: Termopsidae). Sociobiology 50: 895-907

Jackson MA, Mcguire MR, Lacey LA, Wright SP (1997) Liquid culture production of desiccation tolerant blastospores of the bioinsecticidal fungus Paecilomyces fumosoroseus. Mycol Res 101:35-41

Jackson MA, Dunlap CA, Jaronski ST (2010) Ecological considerations in producing and formulating fungal entomopathogens for use in insect biocontrol. BioControl 55:129-145

Lax AR, Osbrink WLA (2003) United States Department of AgricultureAgriculture Research Service research on targeted management of the Formosan subterranean termite Coptotermes formosanus Shiraki (Isoptera: Rhinotermitidae). Pest Manag Sci 59:788-800

Mburu DM, Ochola L, Maniania NK, Njagi PGN, Gitonga LM, Ndung'u MW, Wanjoya AK, Hassanali A (2009) Relationship between virulence and repellency of entomopathogenic isolates of Metarhizium anisopliae and Beauveria bassiana to the termite Macrotermes michaelseni. J Insect Physiol 55:774-780

Mburu DM, Maniania NK, Hassanali A (2013) Comparison of volatile blends and nucleotides sequences of two Beauveria bassiana isolates of different virulence and repellency towards the termite Macrotermes michealseni. J Chem Ecol 39:101-108

Mulrooney JE, Wagner TL, Shelton TG, Peterson CJ, Gerarad PD (2007) Historical review of termite activity at forest service termiticide test sites from 1971 to 2004. J Econ Entomol 100: 488-494

Prestage JJ, Slifer EH, Stephens LB (1963) Thin-walled sensory pegs on the antenna of the termite worker, Reticulitermes flavipes. Ann Entomol Soc Am 56:874-878

Rath AC (2000) The use of entomopathogenic fungi for control of termites. Biocontrol Sci Tech 10:563-581

Rocha L, Moreira GRP, Redaelli LR (2007) Morphology and distribution of antennal sensilla of Gryon gallardoi (Brèthes) (Hymenoptera: Scelionidae) females. Neotrop Entomol 36:721-728

Roode JC, Lefévre T (2012) Behavioral immunity in insects. Insects 3: 789-820

Schmidt-Büsser D, Mv A, Guerin PM (2009) Host plant volatiles serve to increase the response of male European grape berry moths, Eupoecilia ambiguella, to their sex pheromone. J Comp Physiol A 195:853-864

Schroeder R, Hilker M (2008) The relevance of background odor in resource location by insects: a behavioral approach. Bioscience 58 : $308-316$

Stamets P (2012) Controlling zoonotic disease vectors from insects and arthropods using preconidial mycelium and extracts of preconidial mycelium from entomopathogenic fungi. U.S. Patent 2012/0039976 A1

Staples JA, Milner RJ (2000) A laboratory evaluation of the repellency of Metarhizium anisopliae conidia to Coptotermes lacteus (Isoptera: Rhinotermitidae). Sociobiology 36:133-148

Steinbrecht (1999) Chapter V olfactory receptors. In: Eguch E, Tominaga $\mathrm{Y}$ (eds) Atlas of arthropod sensory receptors. Springer, Tokyo, pp $155-176$

Sun J, Fuxa JR, Richter A, Ring D (2008) Interactions of Metarhizium anisopliae and tree-based mulches in repellence and mycoses against Coptotermes formosanus (Isoptera: Rhinotermitidae). Environ Entomol 37:755-763

Tarumingkeng RC, Coppel HC, Matsumura F (1976) Morphology and ultrastructure of the antennal chemoreceptors and mechanoreceptors of worker Coptotermes formosanus Shiraki. Cell Tissue Res 173: 173-178

Varm A, Kolli BK, Paul J, Saxena S, König H (1994) Lignocellulose degradation by microorganisms from termite hills and termite guts: a survey on the present state of art. FEMS Microbiol Rev 15:9-28

Vega FE, Goettel MS, Blackwell M, Chandler D, Jackson MA, Keller S, Koike M, Maniania NK, Monzon A, Ownley BH, Pell JK, Rangel DEN, Roy HE (2009) Fungal entomopathogens: new insights on their ecology. Fungal Ecol 2:149-149

Verma M, Sharma S, Prasad R (2009) Biological alternatives for termite control: a review. Int Biodeterior Biodegrad 63:959-972

Webb B (2012) Cognition in insects. Phil Trans R Soc B 367:2715-2722

Webster B, Bruce T, Pickett J, Hardie J (2010) Volatiles functioning as host cues in a blend become nonhost cues when presented alone to the black bean aphid. Anim Behav 79:451-457 
Wright SP, Jackson MA, De Kock SL (2003) Use of Paecilomyces spp. as pathogenic agents against substerranean termites. US patent number $6,660,291$

Yaginuma K (1990) Detection of fungi to peach fruit moth, Carposina niponensis Walsingham from soil. Bull Fruit Tree Res STNS 17:7789 (in Japanese with English summary)

Yanagawa A, Yokohari F, Shimizu S (2008) Defense mechanism of the termite, Coptotermes formosanus Shiraki, to entomopathogenic fungi. J Invertebr Pathol 97:165-170

Yanagawa A, Yokohari F, Shimizu S (2009a) The role of antennae in removing entomopathogenic fungi from cuticle of the termite, Coptotermes formosanus. J Insect Sci 9:6

Yanagawa A, Shimizu S, Noma K, Nishikawa M, Ogino K, Yokohari F (2009b) Classification and distribution of antennal sensilla of the termite, Coptotermes formosanus (Isoptera: Rhinotermitidae). Sociobiology 54:327-349

Yanagawa A, Yokohari F, Shimizu S (2010) Influence of fungal odor on grooming behavior of the termite, Coptotermes formosanus Shiraki. J Insect Sci 10:4
Yanagawa A, Fujiwara-Tsujii N, Akino T, Yoshimura T, Yanagawa T, Shimizu S (2011a) Behavioral changes in the termite, Coptotermes formosanus (Isoptera), inoculated with six fungal isolates. $\mathrm{J}$ Invertebr Pathol 107:100-106

Yanagawa A, Fujiwara-Tsujii N, Akino T, Yoshimura T, Yanagawa T, Shimizu S (2011b) Musty odor of entomopathogens enhances disease-prevention behaviors in the termite Coptotermes formosanus. J Invertebr Pathol 108:1-6

Yanagawa A, Fujiwara-Tsujii N, Akino T, Yoshimura T, Yanagawa T, Shimizu S (2012) Odor aversion and pathogen-removal efficiency in grooming behavior of the termite Coptotermes formosanus. PLoS One 7:e47412

Ziesmann J (1996) The physiology of an olfactory sensillum of the termite Schedorhinotermes lamanianus: Carbon dioxide as a modulator of olfactory sensitivity. J Comp Physiol 179:123133

Zoberi MH (1995) Metarhizium anisopliae a fungal pathogen of Reticulitermes flavipes (Isoptera: Rhinotermitidae). Mycologia 87: 354-359 